\title{
Prevalence of symptoms and risk of sleep apnea in Dubai, UAE
}

This article was published in the following Dove Press journal:

International Journal of General Medicine

5 March 2013

Number of times this article has been viewed

\section{Bassam Mahboub \\ Shahid Afzal \\ Hassan Alhariri \\ Ashraf Alzaabi \\ Mayank Vats \\ Annie Soans}

Sleep Disorders Center, Department of Medicine, Rashid Hospital, Dubai Health Authority, Dubai, United Arab Emirates
Correspondence: Hassan Alhariri

Sleep Disorders Center,

Department of Medicine,

Rashid Hospital, Dubai Health

Authority, PO Box 4545,

Dubai, United Arab Emirates

Email halhariri@dha.gov.ae
Purpose: The United Arab Emirates (UAE) ranks 18th on the 2007 Forbes list of fattest countries with $68.3 \%$ of its citizens with an unhealthy weight and it is well known that weight gain and obesity are important determinants in the progression of obstructive sleep apnea syndrome (OSAS). The purpose of this study is to estimate the prevalence of symptoms and risk of OSAS in the primary health care setting in Dubai, and the relationship between obesity and sleep apnea.

Methods: In this prospective survey, a trained medical nurse administered the Berlin Questionnaire to a consecutive random sample of patients in the age group older than 14 years, who attended the primary health care center in Dubai Health Authority, Dubai, UAE, from September 2011 to March 2012. Based on the questionnaire answers, individuals were classified into high risk and low risk groups for OSAS.

Results: Based on the responses and measurement of the Berlin Questionnaire of 1214 subjects studied, $58 \%(n=704)$ of the respondents were female, while $42 \%(n=510)$ were male. Two-hundred-fifty-four respondents met the criteria for the high risk scoring. This gives a prevalence rate of $20.9 \%$ (out of which $22.9 \%$ of the male respondents were high risk for OSAS, while $19.5 \%$ of the females were high risk for OSAS), while the remainder of the participants were classified as low risk. The overall mean age of the high risk for OSAS female respondents was 39.95 years (standard deviation [SD] 11.73 years) and was 41.18 years (SD 14.95 years) for male respondents The highest prevalence was observed between age 51 to 60 in both genders. Seventy percent of the high risk group had a body mass index (BMI) $\geq 30 \mathrm{~kg} / \mathrm{m}^{2}$ and nearly $75 \%$ of the low risk group had a BMI $<30 \mathrm{~kg} / \mathrm{m}^{2}$, and the mean BMI was $32.06 \mathrm{~kg} / \mathrm{m}^{2}\left(\mathrm{SD} 5.67 \mathrm{~kg} / \mathrm{m}^{2}\right)$ for males and $33.59 \mathrm{~kg} / \mathrm{m}^{2}$ (SD $6.44 \mathrm{~kg} / \mathrm{m}^{2}$ ) for females.

Conclusion: In the primary health care setting, the prevalence of symptoms of OSAS among adult UAE citizens is very high, and UAE patients are at risk for OSAS and may benefit from proper evaluation for OSAS.

Keywords: obstructive sleep apnea, snoring, daytime sleepiness, prevalence primary care, Berlin Questionnaire, Dubai

\section{Introduction}

Obstructive sleep apnea syndrome (OSAS) consists of episodes in which respiration ceases during sleep from the repeated collapse of the upper airway. The most common cause of this is the partial or complete stoppage of the flow of air due to the relaxation of the muscles which surround the throat and tongue. Although a detailed discussion of the pathophysiology of airflow obstruction in OSAS is outside the scope of this article, it is clear that upper airway collapse most often results from a combination of anatomic factors that predispose the airway to collapse during inspiration, plus 
neuromuscular compensation that is insufficient during sleep to maintain airway patency. The relative contribution of anatomic versus neuromuscular factors is likely to vary greatly among individuals and may vary considerably among groups defined on the basis of age, gender, body habits, race, ethnicity, and overweightness. The prevalence of OSAS is increasing among overweight and obese patients and it is well known that weight gain and obesity are important determinants in the progression of OSAS. ${ }^{1}$

Obesity is a growing health concern in the United Arab Emirates (UAE) with health officials stating that it is one of the leading causes of preventable deaths in the UAE and the UAE ranks 18th on a 2007 Forbes list of fattest countries with $68.3 \%$ of its citizens with an unhealthy weight. ${ }^{2}$ Obesity is 2.3-fold higher among UAE males and females at 14 years compared to international standards, and increases to 3.6 times at 18 years of age in males and to 1.9 times in females. ${ }^{3}$ This obesity in the UAE may be related to cultural influences. The traditional dress in the Middle East is a contributing factor of obesity due to the wearing of loose, flowing garments such as the dish-dash or abayas. Excess weight gained goes relatively unnoticed as people are not wearing close fitting garments, and due to extremely high temperatures up to $50^{\circ} \mathrm{C}$ for a large part of the year in the last 3 years, outdoor activities may be limited and therefore inactivity and boredom can lead to excessive calorie consumption resulting in weight gain.

Obstructive sleep apnea syndrome is a common medical condition with significant adverse medical and public health consequences. Primary care has a central role for recognizing cases of OSAS in the community. ${ }^{4}$ Patients attending primary care clinics tend to have a higher risk for OSAS because these patients often have chronic illnesses that are associated with OSAS. Population-based epidemiologic studies have uncovered the high prevalence and wide spectrum of severity of undiagnosed obstructive sleep apnea, and have consistently found that even mild obstructive sleep apnea is associated with significant morbidity and mortality causing an additional burden on the public health service, and it is a potentially disabling condition. The community prevalence of symptoms and/or signs of OSAS varies by region and by country. ${ }^{5}$ In the United States, an estimated $9 \%$ and $24 \%$ of women and men, respectively, aged 30 to 60 years have at least mild OSAS. ${ }^{6}$ In other Western countries, the overall prevalence of mild and moderate OSAS is estimated at $20 \%$ and 7\%, respectively. ${ }^{5}$ In New Delhi, a community-based study reported a prevalence of $14 \%$ for OSAS in middle-aged men. ${ }^{7}$ In the Middle East, one study was done in Jordan and it showed that the high risk of obstructive sleep apnea was present in 106/554 (19.1\%) of men and in 96/651(14.7\%) of women $(P=0.042) .{ }^{8}$ No data on the prevalence of OSAS or the relationship between obesity and OSAS in the UAE or Dubai have been reported.

The practice of sleep medicine in Dubai began in the last 3 years and it is a relatively new specialty in the medical community. Since its inception, the specialty has grown, and now it is important to assess the prevalence of this disease in this community so this study performed a standardized survey of primary care outpatients from a diverse socioeconomic range to measure the prevalence of symptoms of obstructive sleep apnea among Dubai residents (UAE citizens and expatriates) of both genders. The data will demonstrate to the local authorities that public health initiatives with clinical support are warranted to reduce the burden of OSAS; and proper evaluation for OSAS by the health care workers is urgently needed; and expansion of sleep service in this community is needed for appropriate counseling for the high risk cases of OSAS.

\section{Participants}

The study was approved by the ethics committee of the Dubai Health Authority and the participants were selected from consecutive patients who were $>14$ years of age, regardless of the reason for the visit to primary care centers in the Dubai Health Authority, which is the main Dubai government department which governs health care, medical policy, and strategy in Dubai, and monitors public and private hospitals, clinics, and medical centers in Dubai.

\section{Materials and methods}

We used the Berlin Questionnaire as a screening tool to identify subjects who are at high risk or low risk for OSAS by identifying snoring behavior, daytime sleepiness, obesity, and hypertension. ${ }^{9}$ The questionnaire was developed in April 1996 in Berlin, Germany, it is a simple instrument that has been extensively studied in primary care settings and has shown very high positive predictive value $(89 \%)$ with a reasonable sensitivity and specificity of $86 \%$ and $77 \%$, respectively. ${ }^{10}$

Patients were also asked to provide information on age, weight, height, gender, and ethnicity, and the information (specifically height and weight) was verified by qualified medical staff.

Respondents were classified as either high risk or low risk for sleep apnea based on their responses in three symptom categories. To score high for OSAS, an individual's 
questionnaire must have had positive scores in at least two of the three categories. Those patients who denied having symptoms with such frequency, who did not report symptoms to permit risk assessment, or who qualified in only one category were placed into the low risk group. ${ }^{11,12}$ Height was measured by using a height meter, while a weighing scale was used for measuring the weight to the nearest kilogram. Body mass index (BMI) was calculated using weight in kilograms over height in meters squared $\left(\mathrm{kg} / \mathrm{m}^{2}\right)$. The patients were asked to complete the questionnaire in the office in the primary health care center; then it was sent to the local study group specialist. The questionnaire was offered in English (with an Arabic translation form).

\section{Statistical analysis}

Differences between the high risk and low risk groups for OSAS were analyzed using Statistical Package for Social Sciences (IBM Corporation, Armonk, NY, USA). Multivariate analysis of factors associated with high risk for OSAS was conducted using binary logistic regression.

\section{Results and demographics}

One-thousand-two-hundred-fourteen questionnaires were distributed. All respondents were included in this analysis.

Based on the responses and measurement of the Berlin Questionnaire of the 1214 subjects studied, 58\% $(\mathrm{n}=704)$ of the respondents were female, while $42 \%(n=510)$ were male, with ages ranging from 14 to 81 years. The overall mean age of female respondents was 35.87 years (standard deviation [SD] 12.19 years) and the overall mean age of male respondents was 36.76 years (SD 14.74 years). The overall mean age of both male and female respondents was 36.25 years (SD 13.32 years). Mean BMI was $27.86 \mathrm{~kg} / \mathrm{m}^{2}$ (SD $5.69 \mathrm{~kg} / \mathrm{m}^{2}$ ) for males and $28.53 \mathrm{~kg} / \mathrm{m}^{2}\left(\mathrm{SD} 6.49 \mathrm{~kg} / \mathrm{m}^{2}\right)$ for females. The overall mean BMI of both male and female respondents was $28.25 \mathrm{~kg} / \mathrm{m}^{2}$ (SD $\left.6.17 \mathrm{~kg} / \mathrm{m}^{2}\right)$. Table 1 shows the age and BMI of all respondents.

Table I All respondents - age and BMI

\begin{tabular}{|c|c|c|c|c|c|}
\hline & $\mathbf{N}$ & Minimum & Maximum & Mean & SD \\
\hline \multicolumn{6}{|c|}{ Descriptive statistics } \\
\hline Age & 1214 & 14 & 81 & 36.25 & 13.32 \\
\hline $\mathrm{BMI}$ & 1214 & 13.85 & 57.04 & 28.25 & 6.17 \\
\hline Age of females & 704 & 14 & 75 & 35.87 & 12.19 \\
\hline BMI of females & 704 & 13.85 & 57.04 & 28.53 & 6.49 \\
\hline Age of males & 510 & 14 & 81 & 36.76 & 14.74 \\
\hline $\mathrm{BMI}$ of males & 510 & 14.87 & 49.46 & 27.86 & 5.69 \\
\hline
\end{tabular}

Abbreviations: BMI, body mass index; SD, standard deviation.

\section{Frequency distribution of age}

The study revealed that nearly $74 \%$ of respondents were between the ages of 21 to 50 years. Tables 2 and 3 have more details about the age and gender distributions.

\section{Prevalence of risk of OSAS by age and gender}

Out of 1214 respondents, $20.9 \%(n=254)$ met the criteria for high risk of OSAS, revealing a prevalence rate of approximately $21 \%$, while the remainder of the participants were classified as low risk. Overall, $22.9 \%$ of the male respondents were high risk for OSAS, while $19.5 \%$ of the females were high risk for OSAS (Table 4).

\section{Prevalence of risk of OSAS by BMI}

Seventy percent of the respondents from the high risk group had a BMI $\geq 30 \mathrm{~kg} / \mathrm{m}^{2}$ and nearly $75 \%$ of the low risk group had a BMI $<30 \mathrm{~kg} / \mathrm{m}^{2}$. Mean BMI was $32.06 \mathrm{~kg} / \mathrm{m}^{2}$ $\left(\mathrm{SD} 5.67 \mathrm{~kg} / \mathrm{m}^{2}\right)$ and $33.59 \mathrm{~kg} / \mathrm{m}^{2}\left(\mathrm{SD} 6.44 \mathrm{~kg} / \mathrm{m}^{2}\right)$ for males and females, respectively (Table 5).

The 254 respondents with high risk of OSAS had a mean age of $40.52 \pm 13.30$ years (range was 14 to 76 years) and a mean BMI of $32.89 \pm 6.13 \mathrm{~kg} / \mathrm{m}^{2}$ (range was 16.45 to $53.86 \mathrm{~kg} / \mathrm{m}^{2}$ ). The 117 male respondents with high risk of OSAS had a mean age of $41.18 \pm 14.96$ years (range was 14 to 76 years) and a mean BMI of $32.06 \pm 5.67 \mathrm{~kg} / \mathrm{m}^{2}$ (range was 18.94 to $49.46 \mathrm{~kg} / \mathrm{m}^{2}$ ). The 137 female respondents with high risk of OSAS had a mean age of $39.95 \pm 11.73$ years (range was 14 to 75 years) and a mean BMI of $33.59 \pm 6.44 \mathrm{~kg} / \mathrm{m} 2$ (range was 16.59 to $53.86 \mathrm{~kg} / \mathrm{m} 2$ ). (Table 6 and Figure 1).

\section{Discussion}

This study is the first large data set providing information collected by a standardized protocol on snoring, sleepiness, and other features associated with sleep apnea across primary health care centers in Dubai, and it demonstrates that OSAS is highly prevalent in the general population of Dubai, as it is in other countries. Nearly $21 \%$ of the respondents in the

Table 2 All respondents - frequency distribution of age

\begin{tabular}{lll}
\hline Age groups & Frequency & Percent \\
\hline 14 to 20 & 121 & 10.1 \\
21 to 30 & 350 & 28.8 \\
31 to 40 & 346 & 28.5 \\
41 to 50 & 198 & 16.3 \\
51 to 60 & 139 & 11.4 \\
Older than 60 & 60 & 4.9 \\
Total & 1214 & 100.0 \\
\hline
\end{tabular}


Table 3 Crosstabs - age groups by gender

\begin{tabular}{|c|c|c|c|}
\hline \multirow{2}{*}{$\begin{array}{l}\text { Age group } \\
\text { (years) }\end{array}$} & \multicolumn{2}{|l|}{ Gender } & \multirow[t]{2}{*}{ Total } \\
\hline & Female & Male & \\
\hline \multicolumn{4}{|l|}{14 to 20} \\
\hline Count & 58 & 63 & $12 \mid$ \\
\hline$\%$ within gender & $8.3 \%$ & $12.2 \%$ & $10.1 \%$ \\
\hline \multicolumn{4}{|l|}{21 to 30} \\
\hline Count & 210 & 140 & 350 \\
\hline$\%$ within gender & $29.8 \%$ & $27.5 \%$ & $28.8 \%$ \\
\hline \multicolumn{4}{|l|}{31 to 40} \\
\hline Count & 212 & 134 & 346 \\
\hline$\%$ within gender & $30.1 \%$ & $26.3 \%$ & $28.5 \%$ \\
\hline \multicolumn{4}{|l|}{$4 \mid$ to 50} \\
\hline Count & 122 & 76 & 198 \\
\hline$\%$ within gender & $17.3 \%$ & $14.9 \%$ & $16.3 \%$ \\
\hline \multicolumn{4}{|l|}{51 to 60} \\
\hline Count & 80 & 59 & 139 \\
\hline$\%$ within gender & $11.4 \%$ & $11.6 \%$ & $11.4 \%$ \\
\hline \multicolumn{4}{|l|}{ Older than 60} \\
\hline Count & 22 & 38 & 60 \\
\hline$\%$ within gender & $3.1 \%$ & $7.5 \%$ & $4.9 \%$ \\
\hline \multicolumn{4}{|l|}{ Total } \\
\hline Count & 704 & 510 & 1214 \\
\hline$\%$ within gender & $100.0 \%$ & $100.0 \%$ & $100.0 \%$ \\
\hline
\end{tabular}

study were categorized as high risk of OSAS (ie, $22.9 \%$ and $19.5 \%$ of the male and female respondents, respectively).

Association of males with risk of OSAS is well described. Community-based studies from Western countries have reported OSAS is more common in males compared with females, and in Jordan, the high risk of obstructive sleep apnea was present in 106/554 (19.1\%) of men and in 96/651(14.7\%) of women $(P=0.042) .{ }^{8}$ The findings of our study are really striking, showing higher prevalence of OSAS in the female respondents compared to other studies in the Gulf region (prevalence of high risk for OSAS in female respondents was $19.5 \%$ in our study vs $14.7 \%$ in the Jordanian study), which indicates that the females in Dubai are more prone to OSAS

Table 4 Categorization of respondents at high risk and low risk of OSAS

\begin{tabular}{|c|c|c|c|}
\hline \multirow[t]{2}{*}{ Risk } & \multicolumn{2}{|l|}{ Gender } & \multirow[t]{2}{*}{ Total } \\
\hline & Female & Male & \\
\hline \multicolumn{4}{|l|}{ High risk } \\
\hline Count & 137 & 117 & 254 \\
\hline$\%$ within gender & $19.5 \%$ & $22.9 \%$ & $20.9 \%$ \\
\hline \multicolumn{4}{|l|}{ Low risk } \\
\hline Count & 567 & 393 & 960 \\
\hline$\%$ within gender & $80.5 \%$ & $77.1 \%$ & $79.1 \%$ \\
\hline \multicolumn{4}{|l|}{ Total } \\
\hline Count & 704 & 510 & 1214 \\
\hline$\%$ within gender & $100.0 \%$ & $100.0 \%$ & $100.0 \%$ \\
\hline
\end{tabular}

Abbreviation: OSAS, obstructive sleep apnea syndrome.
Table 5 Correlation between BMI and risk stratification for OSAS

\begin{tabular}{|c|c|c|c|}
\hline \multirow[t]{2}{*}{ BMI grouping } & \multicolumn{2}{|l|}{ Risk } & \multirow[t]{2}{*}{ Total } \\
\hline & High risk & Low risk & \\
\hline \multicolumn{4}{|l|}{$<30 \mathrm{~kg} / \mathrm{m}^{2}$} \\
\hline Count & 75 & 717 & 792 \\
\hline$\%$ within high risk or low risk & $29.5 \%$ & $74.7 \%$ & $65.2 \%$ \\
\hline \multicolumn{4}{|l|}{$\geq 30 \mathrm{~kg} / \mathrm{m}^{2}$} \\
\hline Count & 179 & 243 & 422 \\
\hline$\%$ within high risk or low risk & $70.5 \%$ & $25.3 \%$ & $34.8 \%$ \\
\hline Count & 254 & 960 & 1214 \\
\hline$\%$ within high risk or low risk & $100.0 \%$ & $100.0 \%$ & $100.0 \%$ \\
\hline
\end{tabular}

risk compared to other females in the Middle East or other regions in the world, and even though OSAS is a male dominant disorder, we noticed a higher than expected prevalence of OSAS in the female respondents in Dubai.

\section{Obesity was a strong predictor of OSAS risk}

A population-based study in the United States revealed that obesity was a strong predictor of OSAS risk. ${ }^{13}$ Among obese subjects $\left(B M I \geq 30 \mathrm{~kg} / \mathrm{m}^{2}\right), 59 \%$ of subjects were at high risk of OSAS. In a study of a Korean population, it was shown that a significant percentage of the subjects were not obese but still had OSAS. This led the researchers to speculate that other risk factors, such as content/distribution of body fat and anatomical structure of the upper airway, may be responsible for the higher prevalence of OSAS in the Korean population. Our study also revealed a close association between high BMI and the risk of OSAS in the population of Dubai; among obese subjects (BMI $\left.\geq 30 \mathrm{~kg} / \mathrm{m}^{2}\right), 70 \%$ were at high risk of OSAS and nearly $75 \%$ of the low risk group had a $\mathrm{BMI}<30 \mathrm{~kg} / \mathrm{m}^{2}$, which indicates obesity in Dubai is a very strong predictor of OSAS risk.

Table 6 All high risk respondents - BMI summaries as per age groups

\begin{tabular}{lllll}
\hline $\begin{array}{l}\text { Age groups } \\
\text { (years) }\end{array}$ & $\begin{array}{l}\text { Female } \\
\text { (n) }\end{array}$ & Mean \pm SD & $\begin{array}{l}\text { Male } \\
\text { (n) }\end{array}$ & Mean \pm SD \\
\hline 14 to 20 & 5 & $28.51 \pm 10.84$ & 6 & $36.17 \pm 7.96$ \\
21 to 30 & 28 & $33.53 \pm 6.57$ & 23 & $33.62 \pm 6.10$ \\
31 to 40 & 43 & $34.44 \pm 6.33$ & 35 & $30.59 \pm 6.13$ \\
$4 \mid$ to 50 & 33 & $32.63 \pm 6.15$ & 20 & $32.42 \pm 5.45$ \\
$5 \mid$ to 60 & 22 & $34.11 \pm 5.27$ & 21 & $32.39 \pm 3.80$ \\
Older than 60 & 6 & $35.44 \pm 7.80$ & 12 & $30.48 \pm 4.74$ \\
Total & 137 & $33.59 \pm 6.44$ & 117 & $32.06 \pm 5.67$ \\
\hline
\end{tabular}

Abbreviation: SD, standard deviation. 


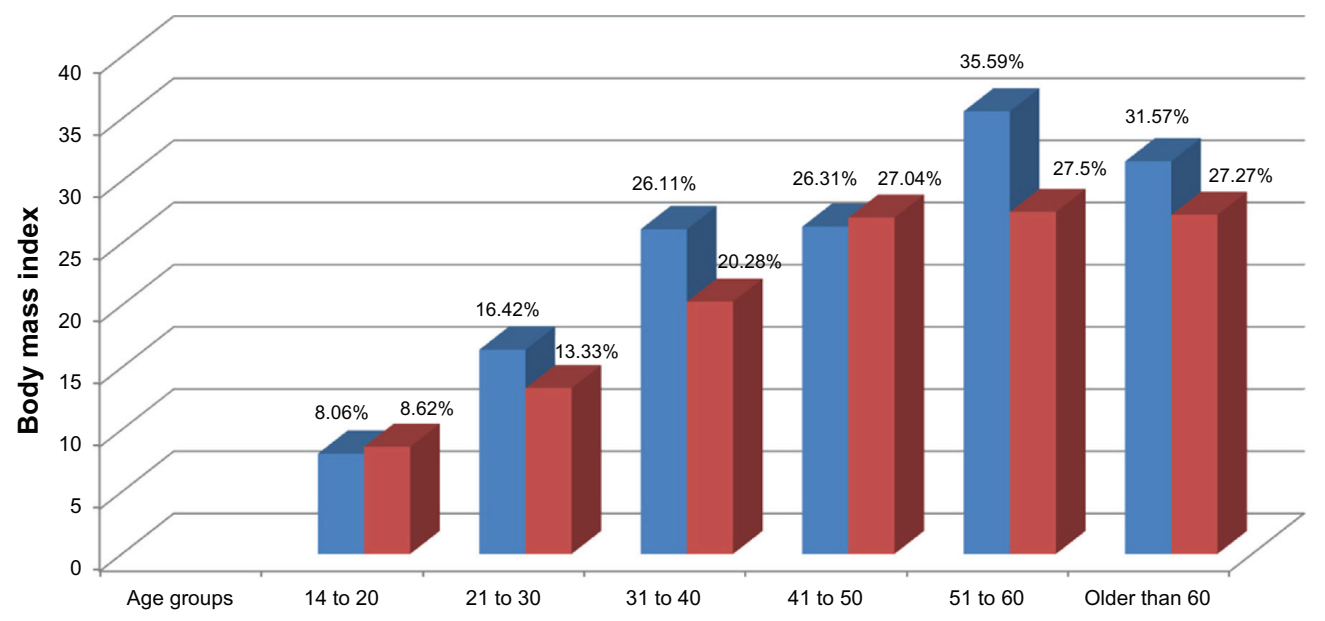

Figure I Prevalence of high risk Berlin Questionnaire scores by age for males (blue) and females (red).

\section{Obesity is more common in female respondents}

Obesity in general is more common in women than men. ${ }^{14}$ In the USA, $24.9 \%$ of women versus $19.9 \%$ of men had a BMI greater than 30. In Saudi Arabia, women are significantly more obese than men, with a prevalence of $44 \%$ and $26.4 \%$, respectively. ${ }^{15}$ In our study, we found that women in Dubai are significantly more obese than men (similar to Saudi Arabia) with a prevalence of $39.63 \%$ and $32.61 \%$, respectively, and the highest BMI of the respondents was noticed in younger male and elderly female respondents. The young male respondents (age group 14 to 20 years) had a mean BMI of $36.17 \mathrm{~kg} / \mathrm{m}^{2}\left(\mathrm{SD} 7.96 \mathrm{~kg} / \mathrm{m}^{2}\right)$ while the elderly female respondents (age group $>60$ years) had the highest BMI among the female respondents with a mean BMI of $35.44 \mathrm{~kg} / \mathrm{m}^{2}\left(\mathrm{SD} 7.80 \mathrm{~kg} / \mathrm{m}^{2}\right)$.

\section{The highest prevalence was noticed in the age group $5 \mathrm{I}-60$ years in both genders}

The overall mean age of the high risk for OSAS female respondents was 39.95 years (SD 11.73 years) and was 41.18 years (SD 14.95 years) for male respondents; and the prevalence increased with age; and the highest prevalence was noticed between ages of 51 to 60 years in both genders; and the high risk of obstructive sleep apnea was present in $35.59 \%$ of men and in $27.5 \%$ of women in this age group.

\section{Limitations of the study}

There are some potential limitations to consider. For example, we did not independently confirm or refute reporting of snoring or daytime sleepiness by the respondents. However, the concordance between patient self-reporting and bed-partner reporting of snoring and apneic episodes is sufficiently high ${ }^{16}$ to believe that there might not be over reporting of these symptoms. The study did not include information on the utility of the Berlin Questionnaire with regards to patient outcome.

The Berlin Questionnaire does not capture all information that a physician might want or seek, nor does it substitute for direct measurements of breathing during sleep (polysomnography). We did not require specialist referral or sleep studies, (which might confirm or exclude the prevalence of OSAS), but the self-report format has the advantages of convenience, simplicity and low cost, and may be more uniform in presentation compared to face-to-face screening.

\section{Conclusion}

In the primary health care setting, the prevalence of symptoms of OSAS among adult UAE citizens and residents is very high. The population of Dubai is at high risk for OSAS and this is a serious public health issue. Patients may benefit from proper screening, evaluation, and appropriate counseling for those at high risk of sleep apnea by the primary health care physicians/workers. In addition, public awareness about the close relationship between obesity and sleep apnea may play a very important role in controlling the prevalence of obesity, and consequently OSAS in Dubai, UAE.

\section{Disclosure}

The authors report no conflicts of interest in this work.

\section{References}

1. Punjabi NM. The epidemiology of adult obstructive sleep apnea. Proc Am Thorac Soc. 2008;5(2):136-143.

2. Streib L. World's Fattest Countries. Forbes. February 8, 2007. Available from: http://www.forbes.com/2007/02/07/worlds-fattest-countriesforbeslife-cx_ls_0208worldfat.html. Accessed January 30, 2013. 
3. Al-Haddad FH, Little BB, Abdul Ghafoor AG. Childhood obesity in United Arab Emirates schoolchildren: a national study. Ann Hum Biol. 2005;32(1):72-79.

4. Dement WC, Netzer NC. Primary care: is it the setting to address sleep disorders? Sleep Breath. 2000;4(1):1-XX.

5. Young T, Peppard PE, Gottlieb DJ. Epidemiology of obstructive sleep apnea: a population health perspective. Am J Respir Crit Care Med. 2002;165(9):1217-1239.

6. Young T, Palta M, Dempsey J, Skatrud J, Weber S, Badr S. The occurrence of sleep-disordered breathing among middle-aged adults. $N$ Engl J Med. 1993;328(17):1230-1235.

7. Sharma SK, Vasudev C, Sinha S, Banga A, Pandey RM, Handa KK. Validation of the modified Berlin questionnaire to identify patients at risk for the obstructive sleep apnea syndrome. Indian J Med Res. 2006; 124(3):281-290.

8. Khassawneh B, Ghazzawi M, Khader Y, et al. Symptoms and risk of obstructive sleep apnea in primary care patients in Jordan. Sleep Breath. 2009;13(3):227-232.

9. Netzer NC, Stoohs RA, Netzer CM, Clark K, Strohl KP. Using the Berlin Questionnaire to identify patients at risk for the sleep apnea syndrome. Ann Intern Med. 1999;131(7):485-491.
10. Netzer NC, Hoegel JJ, Loube D, et al; Sleep in Primary Care International Study Group. Prevalence of symptoms and risk of sleep apnea in primary care. Chest. 2003;124(4):1406-1414.

11. Netzer NC, Stoohs RA, Netzer CM, Clark K, Strohl KP. Using the Berlin Questionnaire to identify patients at risk for the sleep apnea syndrome. Ann Intern Med. 1999;131(7):485-491.

12. Reprinting of the Berlin questionnaire. Sleep Breath. 2000;4: 187-192.

13. Hiestand M, Britz P, Goldman M, Phillips B. Prevalence of symptoms and risk of sleep apnea in the US population: Results from the National Sleep Foundation Sleep in America 2005 poll. Chest. 2006;130(3):780-786.

14. Redline S, Kump K, Tishler PV, Browner I, Ferrette V. Gender differences in sleep disordered breathing in a community-based sample. Am J Respir Crit Care Med. 1994;149(3 Pt 1):722-726.

15. Alotair H, BaHammam A. Gender differences in Saudi patients with obstructive sleep apnea. Sleep Breath. 2008;12(4):323-329.

16. Kump K, Whalen C, Tishler PV, et al. Assessment of the validity and utility of a sleep-symptom questionnaire. Am J Respir Crit Care Med. 1994;150(3):735-741.

\section{Publish your work in this journal}

The International Journal of General Medicine is an international, peer-reviewed open-access journal that focuses on general and internal medicine, pathogenesis, epidemiology, diagnosis, monitoring and treatment protocols. The journal is characterized by the rapid reporting of reviews, original research and clinical studies across all disease areas.
A key focus is the elucidation of disease processes and management protocols resulting in improved outcomes for the patient.The manuscript management system is completely online and includes a very quick and fair peer-review system. Visit http://www.dovepress.com/ testimonials.php to read real quotes from published authors. 